\title{
Обзор нормативно-правового регулирования отношений в газовой отрасли РФ
}

Гудков И.В.*

В настоящем докладе в сжатой форме представлен, во-первых, обзор нормативно-правового регулирования газовой отрасли РФ и, вовторых, сравнительный анализ проектов концепций реформирования российского газового рынка через призму базисного документа, определяющего политику страны в энергетической сфере, - Энергетической стратегии России на период до 2020 г.'

\section{1. Организационная структура и нормативно-правовое} регулирование отношений в отдельных звеньях

\section{производственно-сбытовой цепи}

\section{1. Добыча}

\section{Организационная структура}

Из разведанных запасов газа около $75 \%$ сконцентрировано в одном регионе - Западной Сибири. Три четверти разведанных запасов сосредоточено на 21 крупном месторождении Западной Сибири. Высок потенциал газодобывающих районов Восточной Сибири, Дальнего Востока, п-ова Ямал и шельфовых месторождений арктических морей. В настоящее время ведется работа над программами освоения месторождений данных районов.

Большую часть (около 90\%) российского газа добывает «Газпром» через свои специализированные дочерние газодобывающие общества. В секторе добычи представлены также не аффилированные с «Газпромом», так называемые «независимые» производители газа.

\section{Нормативно-правовое регулирование}

Основы государственного регулирования добычи газа определены в Ф3 от 21 февраля 1992 года № 2395-1 «О недрах»². Разведка и добы-

\footnotetext{
- Гудков Иван Владимирович - аспирант кафедры международных проблем ТЭК Международного института энергетической политики и дипломатии МГИМО (У) МИД России.

${ }^{1}$ УТв. распоряжением Правительства РФ от 28.08.2003 г. № 1234-р.

2 Здесь и далее ссылки на нормативно-правовые акты указаны с учетом внесенных в них изменений по состоянию на 01.09.2005 г.
} 
ча газа требуют получения лицензии на определенных в данном законе условиях и в предусмотренном им порядке.

\section{2. Транспортировка и хранение \\ Cімруктура}

Транспортировка газа осушествляется по принадлежашей «Газпрому» на праве собственности системе магистральных газопроводов, входящей в Единую систему газоснабжения (ЕСГ).

Для осушествления транспортировки газа функционируют 17 дочерних газотранспортных обществ «Газпрома» (все - в организационноправовой форме обществ с ограниченной ответственностью). Газотранспортные общества транспортируют как газ «Газпрома», так и газ независимых производителей газа.

Наряду с транспортировкой газа газотранспортные организации осуществляют деятельность по его хранению. Финансовый учет и отчетность в газотранспортных организациях ведется отдельно по видам деятельности.

Система диспетчерского управления закачкой, транспортировкой и отбором газа осушествляется Центральным производственнодиспетчерским департаментом (ЦПДД), являющимся структурным подразделением администрации «Газпрома».

\section{Нормативно-правовое регулирование}

Деятельность по транспортировке газа по магистральным трубопроводам относится к естественно-монопольному виду деятельности и как таковая является предметом государственного тарифного регулирования.

Основы тарифного регулирования определены в Ф3 от 17 августа 1995 года №147-Ф3 «О естественных монополиях», Ф3 от 31 марта 1999 года №69-Ф3 «О газоснабжении в Российской Федерации», Постановлении Правительства РФ от 29 декабря 2000 года № 1021 «О государственном регулировании цен на газ и тарифов на услуги по его транспортировке на территории РФ». Указанные акты устанавливают принципы и исходные данные расчета тарифов на газотранспортные услуги. Методика их расчета до сих пор не утверждена и находится в стадии разработки.

Государство в лице Федеральной службы по тарифам (ФСТ) устанавливает тарифы на газотранспортные услуги, которые «Газпром» оказывает третьим лицам - независимым организациям. Применяется тарифная система «от пункта к пункту», основанная на расстоянии транспортировки и объеме фактически транспортируемого газа. 
Услуги по транспортировке газа, которые «Газпром» оказывает своим аффилированным организациям, не являются предметом государственного тарифного регулирования.

Раздельные тарифы на услуги по транспортировке газа для независимых и аффилированных организаций будут существовать до перехода к государственному регулированию единых для всех поставшиков газа тарифов.

Что касается хранения газа, то законодательно не установлено требование тарифного регулирования данного вида деятельности. Таким образом, тарифы на услуги по хранению газа могут быть предметом свободных договорных отношений.

Порядок доступа к системе магистральных газопроводов «Газпрома» регулируется Постановлением Правительства от 14 июля 1997 года № 858 «Об обеспечении доступа независимых организаций к газотранспортной системе ОАО «Газпром»». В соответствии с данным Постановлением третьи лица при условии наличия свободной пропускной способности и при соблюдении установленных качественных и технических стандартов имеют право на недискриминационный доступ $к$ системе магистральных газопроводов для поставок газа на внутренний рынок. Обязанность по предоставлению доступа к системе для поставок на экспортные рынки не установлена.

Законодательно не установлена обязанность по предоставлению доступа к системе хранения газа. Таким образом, отношения между операторами систем хранения газа и пользователями являются предметом свободных договорных отношений.

\section{3. Распределение}

\section{Организационная структура}

Газораспределительные сети находятся в собственности многочисленных (более 300) региональных газораспределительных организаций (ГРО), которые осуществляют распределение газа по принадлежащим им распределительным сетям. При этом многие ГРО совмещают деятельность по распределению газа с деятельностью по оптовой закупке газа у производителей и его розничной продаже конечным покупателям.

\section{Нормативно-правовое регулирование}

В соответствии с Постановлением Правительства № 1021 ФСТ устанавливает как тарифы за транспортировку газа по распределительным сетям, так и плату за снабженческо-сбытовые услуги, оказывае- 
мые теми ГРО, которые совмешают функции по распределению и сбыту газа. Данные полномочия ФСТ может делегировать региональным службам.

Доступ к газораспределительным сетям регулируется Положением «Об обеспечении доступа организаций к местным газораспределительным сетям» (утверждено Постановлением Правительства РФ от 24 ноября 1998 года № 1370).

\section{4. Продажа}

\section{Организационная структура}

Внутренний рынок

Как правило, продажа газа на российском рынке конечным потребителям осуществляется компаниями, которые оптом покупают газ у производителей (исключение составляет продажа крупным промышленным потребителям, напрямую подсоединенным к системе магистральных трубопроводов, которые покупают газ непосредственно у производителя). Такими компаниями являются либо ГРО, которые совмешают функцию распределения газа с функцией сбыта, либо специализированные компании, занимающиеся исключительно сбытом.

\section{Внешний рынок}

Поставки газа на экспорт осуществляет исключительно «Газпром» через свое дочернее общество - «Газэкспорт», действующее в качестве комиссионера.

\section{Нормативно-правовое регулирование}

Отношения между российскими поставщиками газа и покупателями регулируются Постановлением Правительства РФ о правилах поставки газа от 5 февраля 1998 года № 162 «Об утверждении правил поставки газа в Российской Федерации». В соответствии с данным Постановлением определен порядок заключения и исполнения договоров поставки газа; установлен круг покупателей, имеющих преимущественное право на заключение таких договоров (к их числу относятся государство и бытовые потребители).

В соответствии с Постановлением Правительства № 1021 ФСТ устанавливает оптовые цены на газ, поставляемый «Газпромом» и собственниками региональных систем газоснабжения на внутренний рынок. Цены устанавливаются разные для двух разных категорий покупателей: промышленности и населению. На газ, реализуемый промышленным потребителям, оптовые цены устанавливаются, как правило, выше, чем на газ, предназначенный для последуюшей реализации 
населению. При этом оптовые цены варьируются также в зависимости от территориального пояса (всего поясов 11). В регионах, находящихся ближе к центрам добычи, цены устанавливаются ниже, чем в удаленных регионах.

Государственное регулирование оптовых цен на газ, поставляемый «Газпромом», будет применяться до перехода к единым для всех поставщиков газа тарифам на услуги по его транспортировке на территории РФ. После такого перехода оптовые цены должны стать предметом свободных договорных отношений.

Специально регулируются розничные цены на газ, поставляемый населению ${ }^{3}$. В случае если население покупает газ, оптовая цена которого регулируется (т.е. газ, поставляемый «Газпромом» и собственниками региональных систем газоснабжения), цена слагается из регулируемой оптовой цены на газ, стоимости услуг по транспортировке газа по газораспределительным сетям и платы за снабженческо-сбытовые услуги. В случае если населению реализуется газ, оптовые цены на который не регулируются (т.е. газ независимых производителей), в расчете рыночных цен, помимо регулируемого тарифа на транспортировку по газораспределительным сетям, учитываются сформировавшиеся рыночные цены на такие объемы газа, а также расходы поставщиков, связанные с поставкой этих объемов населению.

Цены на газ, поставляемый независимыми производителями газа, и экспортные цены не являются предметом государственного регулирования и по общему правилу определяются на свободной рыночной основе.

\section{2. Концепции реформирования газовой отрасли России Положения о направлениях реформирования газовой отрасли России определены Энергетической стратегией России на период до 2020 г. $^{4}$}

Проекты концепции реформирования газовой отрасли разрабатывались на протяжении достаточно длительного времени, начиная с конца 1990-х годов, различными субъектами, представляюшими как государственную власть, так и частный сектор.

${ }_{3}^{3}$ Постановление ФСТ РФ от 23 ноября 2004 года № 194-3/12 «Об утверждении методических указаний по регулированию розничных цен на газ, реализуемый населению".

${ }^{4}$ Утв. Распоряжением Правительства РФ от 28 августа 2003 г. № 1234-р. 
Для демонстрации различных взглядов на пути развития газовой отрасли России исследованы следуюшие проекты концепции:

- Доклад о структурных преобразованиях в добыче и транспортировке газа, подготовленный Министерством экономического развития и торговли РФ (МЭРТ);

- Проект Концепции развития рынка газа, подготовленный «Газпромом»;

- Проект Концепции реформирования газовой отрасли РФ, подготовленный Союзом независимых производителей газа (Союзгаз);

- Проект Концепции реформирования газовой отрасли и развития рынка газа, подготовленный Российским союзом промышленников и предпринимателей (РСПП).

Следует подчеркнуть, что данные документы не имеют юридической силы; содержащиеся в них предложения лишь отражают позиции соответствуюших субъектов и, в отличие от Энергетической стратегии России, не могут быть правовой основой для принятия государственными органами решений при разработке и реализации мер регулирования в газовой отрасли.

Указанные документы находятся в открытом доступе $\mathrm{e}^{5}$. На основании их анализа и обобщения можно сделать вывод о том, что предметом дискуссии являются следующие основные предполагаемые направления реформирования газовой отрасли:

1) структурные преобразования газовой отрасли;

2) преобразования в ценообразовании на рынке газа;

3) преобразования в части доступа третьих лиц к газотранспортной системе.

Также широко обсуждаются вопросы реформирования системы налогообложения в газовой сфере и либерализации рынка акций «Газпрома», но они не являются предметом рассмотрения в настояшей работе.

2.1. Структурные преобразования: модели обособления естественно-монопольных видов деятельности

Энергетическая стратегия достаточно осторожно говорит о структурных преобразованиях в газовой промышленности. Она ограничивается установлением стратегической цели таких преобразований: «повышение экономических результатов отрасли и формирование либерализованного рынка газа» и определением их приоритетных

${ }^{5}$ См. сайт Российского газового общества http://www.gazo.ru/ru/main/document. 
направлений: «повышение прозрачности финансово-хозяйственной деятельности «Газпрома» на основе раздельного учета затрат по видаи деятельности, совериенствование системы внутренней торговли газом... и поэтапный переход к эффективному внутреннему рынку газа».

В отличие от заложенной в Энергетической стратегии идеи о приоритетности применения наиболее мягкой модели структурных преобразований газовой отрасли (разъединение финансовой отчетности по видам деятельности), некоторые концепции предлагают более жесткие модели преобразований, такие как организационное (юридическое) разъединение по видам деятельности и наиболее радикальный вариант: организационное разъединение с изменением собственника на газотранспортные активы.

Однако в «Газпроме» уже проведено юридическое разъединение по видам деятельности: транспортировкой, добычей, сбытом занимаются специализированные дочерние обшества, которые в большинстве случаев не совмещают указанные виды деятельности, а в случае совмещения ведут раздельную финансовую отчетность по видам деятельности 6 .

В числе основных аргументов против жестких структурных преобразований отрасли называются их непропорциональность для достижения поставленной Энергетической стратегией задачи (повышение эффективности отрасли и формирование либерализованного рынка газа), а также серьезные риски, в. т.ч. кредитные и корпоративные, которые могут повлечь радикальные изменения.

2.2. Реформирование ценообразования на газ: от регулируемого - к свободному рынку

Недостаточный уровень регулируемых цен на газ, добываемый «Газпромом», с одной стороны, снижает инвестиционную привлекательность отрасли в целом, с другой - мешает развитию независимых производителей газа, которые, хотя и имеют возможность продавать газ по рыночным ценам, на практике в реальности существенно ограни-

${ }^{6}$ В соответствии с Постановлением Правительства РФ № 1021 на организации, осуществляющие добычу, транспортировку и реализацию природного газа, возложена обязанность с 1 января 2001 года вести раздельный учет продукции (услуг) и затрат на ее производство по следующим видам деятельности: добыча природного газа; услуги по транспортировке природного газа по трубопроводам; хранение природного газа; услуги по поставке (реализации) природного газа. 
чены в этой возможности, так как спрос на их газ в условиях низких регулируемых цен формируется по остаточному принципу.

Таким образом, без реформирования существующей модели ценообразования на газ невозможно эффективное развитие конкуренции в добыче/поставке газа.

На настояший момент законодательно уже заложена основа для реформирования ценообразования: Постановление Правительства № 1021 предусматривает, что государственное регулирование оптовых цен на газ подлежит прекращению при введении единого для всех пользователей системы газотранспортного тарифа.

Энергетическая стратегия предусматривает следующие меры, направленные на формирование либерализованного рынка газа:

- поэтапное повышение цен на газ на внутреннем рынке, переход к реализации газа по рыночным ценам для обеспечения самофинансирования субъектов рынка, объективной оценки потребительских свойств газа;

- переход от регулирования оптовой цены на газ к установлению единого для всех производителей газа тарифа за его транспортировку;

- предоставление потребителям газа адаптационного периода для приспособления к меняюшимся условиям функционирования рынка газа;

- зашита социально чувствительных категорий потребителей от резких колебаний цен на газ;

- развитие инфраструктуры внутреннего рынка для перехода на реализацию газа по рыночным ценам.

Энергетическая стратегия называет конкретные индикаторы требуемого для обеспечения необходимого роста инвестиций повышения цен на регулируемом секторе рынка: в рамках первого этапа регулируемые цены на газ должны достигнуть уровня 40-41 доллара США за 1000 куб. м к 2006 г. и вырасти до 59-64 долларов США за 1000 куб. м к 2010 г.

Что же говорят о реформировании ценообразования различные концепции? В отличие от вопроса о структурных преобразованиях, по вопросу реформирования ценообразования в целом наблюдается принципиальное общее согласие с заложенным в Стратегии подходом. Налицо обшее понимание необходимости пेостепенного перехода от регулируемых цен на газ к договорным. При этом все рассмотренные в настояшей работе концепции исходят из того, что переход 
к свободному рынку не должен быть осуществлен одномоментно; необходим адаптационный переходный период (называются сроки от 8 до 10 лет), в течение которого доля нерегулируемого сектора будет плавно расширяться и параллельно с этим будет повышаться уровень цен на сужающемся регулируемом секторе.

Предметом дискуссии, таким образом, является вопрос не о том, переходить или не переходить к свободному рынку газа, а о формах и механизмах такого перехода.

К дискуссионным относятся также вопросы о степени расширения нерегулируемого сектора, об объеме газа, который в течение переходного периода доминирующий поставщик сможет поставлять на свободный сектор, и условиях такой поставки.

\section{3. Доступ к газотранспортной системе}

\subsection{1. Единыцй газотранспортный тариф}

Условием развития конкуренции в газовой сфере является применение одинаковых правил доступа к системе для всех поставщиков газа. Энергетическая стратегия в качестве необходимой меры государственной политики предусматривает «создание условий для недискриминационного доступа к системе магистральных газопроводов всех участников рынка».

Как было отмечено, законодательно уже заложена основа для перехода к единым газотранспортным тарифам. В настояшее время ведется разработка методики их расчета. Введение единых газотранспортных тарифов послужит началом перехода от регулируемых цен на газ к свободным.

Применяемые в настоящее время газотранспортные тарифы основываются на объеме транспортируемого газа и расстоянии транспортировки (система «от пункта к пункту»). Дискутируются предложения (РСПП; Союзгаз) по внедрению новой тарифной системы, предполагаюшей установление индивидуальных тарифов для отдельных пунктов входа в систему и выхода из нее без привязки к расстоянию транспортировки (система «вход-выход»). В этом отношении важно просчитать, возможно ли эффективно устранить проблему перекрестного субсидирования ближними потребителями дальних потребителей в рамках системы «вход-выход».

\subsection{2. Инвестиции в развитие системы}

Введение единых газотранспортных тарифов, внедрение свободного рынка газа создает предпосылки для развития независимых произ- 
водителей газа. По прогнозам Энергетической стратегии, доля независимых производителей увеличится с текуших приблизительно $10 \%$ до $20 \%$ к 2020 г.

Расширение добычи независимыми производителями неизбежно потребует развития газотранспортной системы, которая уже на сегодняшний день не способна удовлетворить спрос в полном размере. Вопрос состоит в том, кто должен финансировать расширение существуюшей системы и строительство новых газопроводов. Что говорит по этому поводу Энергетическая стратегия? В качестве меры государственной политики она предусматривает «...сохранение ЕСГ в качестве единого инфраструктурного технологического комплекса, ее развитие за счет сооружения и подключения к ней новых объектов любых форм собственности (в том числе на основе долевого участия)».

В качестве возможных форм и условий участия независимых производителей газа в развитии газотранспортной системы концепции называют:

- предоставление независимым производителям гарантированного права доступа в систему при условии их участия в финансировании проектов по развитию газотранспортной системы;

- компенсация инвестиционных расходов собственника газотранспортной системы на ее развитие в форме единовременной платы за подключение либо в форме платы за пользование расширенными мощностями системы на основе долгосрочных гарантированных договоров на условиях «транспортируй или плати».

\subsection{3. Поставки на экспорт}

Энергетическая стратегия прямо предусматривает необходимость сохранения «единого канала экспорта природного газа». Смысл сохранения единого канала экспорта газа состоит в том, чтобы не допустить конкуренцию российского газа с российским газом на экспортном рынке и, соответственно, избежать падения экспортных цен на российское «голубое топливо».

В концепциях отражены разные подходы к пониманию того, что означает единый экспортный канал: одна трактовка предполагает, что на экспорт может поставляться только газ, собственником которого является «Газпром», при этом доходы от экспорта могут быть разделены между всеми российскими производителями газа пропорционально доле их добычи при условии несения всеми производителями пропорциональной социальной нагрузки (МЭРТ). Другая трактовка 
(Союзгаз, РСПП) предполагает, что хотя экспорт и должен осушествляться исключительно через единого посредника (Газэкспорт), но на внешний рынок может поставляться также газ независимых производителей в объеме, пропорциональном объему их добычи или доле в удовлетворении внутрироссийского спроса и при условии согласования цены реализации с «Газпромом», которая в любом случае не должна быть ниже рыночной цены в регионе реализации.

Подводя итог вышеизложенному краткому обзору концепций, хотелось бы отметить, что ключевым является вопрос о механизмах, которые позволили бы в условиях конкурентного рынка добычи/поставок газа обеспечить выполнение социально значимых задач (в частности, таких, как обеспечение надежности поставок неотключаемым потребителям, развитие регионов, защита окружающей среды).

Проблема нахождения баланса между законами работы конкурентного рынка и необходимостью выполнения социально значимых задач в энергетической сфере является одной из центральных дискуссионных проблем в контексте реформирования газовых отраслей зарубежных стран. В этой связи интересен опыт ЕС, которое на законодательном уровне признает приоритет социально значимых задач перед требованиями свободной конкуренции. Практическим последствием такого признания является наделение предприятий, на которые возложено выполнение социально значимых задач, особым статусом, позволяющим им иметь необходимую зашиту для их эффективного выполнения. 